\title{
A sistematização de informações: roupas funcionais através do mapa mental
}

The systematization of information: functional clothes through the mind map

\section{Eliete Auxiliadora Assunção Ourives}

Doutora em Engenharia de Produção - UFSC elieteourives@gmail.com

Luiz Fernando Gonçalves de Figueiredo Doutor em Engenharia de Produção - UFSC Iffigueiredo2009@gmail.com

\section{Milton Luiz Horn Vieira}

Doutor em Engenharia de Produção - UFSC milton@cce.ufsc.br

\section{Victor Nassar Palmeria Oliveira \\ Doutorando em Design - UFSCLondon victornassar@gmail.com \\ Jonatan Nishida}

Mestrando em Design - UFSC jounishida@gmail.com

\section{Alais Souza Ferreira}

Estudante de Especialização em Marketing Criativo - UNIVALI alais.ferreira@live.com

\section{Ludimilla Gonçalves de Figueiredo}




\section{A sistematização de informações: roupas funcionais através do mapa mental}

The systematization of information: functional clothes through the mind map

Eliete Auxiliadora Assunção Ourives, Luiz Fernando Gonçalves de Figueiredo, Victor Nassar Palmeria Oliveira, Jonatan Nishida, Alais Souza Ferreira, Milton Luiz Horn Vieira e Ludimilla Gonçalves de Figueiredo

\section{Resumo}

Atualmente, verifica-se a evolução no design do vestuário feminino, visando ao bem-estar, conforto e qualidade de vida. Porém, as mulheres ainda reclamam do desconforto do movimento das mamas durante as atividades físicas desenvolvidas em chão de fábrica e práticas desportivas, entre outras atividades. Esse desconforto, segundo as mulheres, aumenta durante o período menstrual. Portanto, estruturar as informações a respeito do tema é importante, já que irá adequar os projetos de roupas funcionais para essas atividades. O mapa mental é uma ferramenta apropriada para isso, pois auxilia o processo de organização do pensamento e a compreensão das informações sobre determinado assunto. Com isso, este trabalho objetiva estruturar informações para requisitos de projeto com foco na roupa funcional feminina. $\mathrm{O}$ método de pesquisa tem caráter descritivo e exploratório. Ao final, este trabalho apresentou diretrizes projetuais de roupa funcional feminina por meio do processo de análise do mapa mental.

Palavras- chave: roupa funcional, mapa mental, diretrizes de projeto.

\begin{abstract}
Currently, if checks the evolution in women's clothing design aiming at the well-being, comfort and quality of life. However, women still complain of discomfort of breast movement during physical activities carried out in factory floors and sporting activities, among other activities. This discomfort, according to the women, increases during the menstrual period. Therefore, to structure the information on the subject is important, because it will suit the functional clothing designs for these activities. The mind map is a tool suitable for this because assists the organization process of thought and understanding of the information about a particular subject. With that, this work aims to structure information for project requirements with a focus on functional female clothing. The method of research is descriptive and exploratory character. In the end, this work presented project guidelines of functional guidelines female clothing through the process of analysis the mind map.
\end{abstract}

Keywords: functional clothes, mind map, project guidelines. 


\section{INTRODUÇÃO}

Com a presença das mulheres no ambiente da produção industrial, a literatura tem relatado as mudanças ocorridas no design do vestuário feminino, seja pela simplificação do vestir ou pela masculinização do traje, busca de conforto, etc., decorrentes de fatores sociais, econômicos e produtivos. Verifica-se que as discussões sobre o design do vestuário feminino têm se concentrado com maior ênfase nos aspectos estéticos da configuração da roupa, inerentes aos desdobramentos da moda, sem se preocupar com os aspectos funcionais da roupa ajustados à antropometria do corpo feminino.

Nesse contexto, a categoria de roupas esportivas possui diversos modelos, como as roupas de compressão que se preocupam com os aspectos funcionais ajustados à antropometria do corpo. Elas ajudam a manter a postura correta, a manter temperatura corporal ideal e a diminuir o atrito entre os músculos. Os modelos variam muito: para os países frios eles mantêm o calor, para os quentes deixam o suor evaporar e possuem tecidos que ajudam a pele respirar, além das costuras que são baixas para não machucar a pele. As roupas viraram aliadas na qualidade de vida e do bem-estar, com a proliferação do chamado vestuário inteligente, visando à atividade de projeto para roupas funcionais.

A utilização de tecnologia objetivando potencializar o vestuário feminino encontra-se em evolução, tornando-o eficiente, interativo e funcional. Nesse aspecto, a pesquisa e estruturação de informações são importantes para estabelecer diretrizes de requisitos para o projeto, formando uma base de dados referente às roupas funcionais. Essa base de dados irá contribuir na melhoria das roupas funcionais, minimizando o desconforto do movimento das mamas das mulheres, durante a realização de atividades físicas - desenvolvidas em chão de fábrica e práticas desportivas, como andar rapidamente, correr e alguma outra atividade que envolva o movimento das mamas. Além disso, segundo as mulheres, esse desconforto aumenta durante o período menstrual.

Neste sentido, a relevância deste estudo pode ser estabelecida em consequência de dois parâmetros: o primeiro é voltado para a área acadêmica específica na qual a discussão teórica é desenvolvida; e o segundo, a pesquisa que explora o uso de mapas mentais na estruturação e planejamento de informações, apresentando diretrizes 
do processo de análise, direcionadas à construção lógica de ações na pesquisa de roupas funcionais femininas.

No primeiro parâmetro, buscam-se instrumentos com a finalidade de realizar um controle dos procedimentos efetuados no processo, identificando as oportunidades de aperfeiçoamento na pesquisa de roupas funcionais femininas. No segundo parâmetro, que é o estudo prático, fortifica-se e integra-se mais no ambiente de pesquisa científica, pois, pela aplicação prática, utilizando os mapas mentais, apresenta e demonstra a importância da necessidade de sistematização do tema, contribuindo no processo de busca de informações importantes para o direcionamento de ações sobre a pesquisa de roupas funcionais femininas.

O presente estudo, ao enveredar neste campo de pesquisa, estará contribuindo para buscar diretrizes que possam orientar o processo de pesquisa, assim como permitirá gerar discussões práticas sobre o tema, ajudando o seu desenvolvimento e aproximando a ciência da realidade acadêmica.

\section{MAPA MENTAL}

O método conhecido como "Mapa Mental", foi criado pelo inglês Tony Buzzan, década de 70, e é adotado por profissionais das mais variadas áreas do conhecimento. Ele tenta representar, de forma gráfica, como as ideias se organizam e se associam em torno de um elemento principal, criando uma linha de raciocínio lógico e espontâneo. Por isso, o mapa mental é considerado uma técnica que auxilia o processo de organização do pensamento, ou seja, ajuda a hierarquizar o pensamento e a compreender melhor as informações sobre determinado conteúdo. (BUZZAN, 2005)

O Mapa Mental é utilizado desde a gestão de informações, compreensão e solução de problemas, memorização e aprendizado, até a criação de livros, elaboração de palestras, ferramenta de brainstorming e no auxílio da gestão estratégica de empresas. Essa ferramenta beneficia àqueles que aprendem visualmente, mas os seus benefícios são inúmeros, visto que são versáteis e possibilitam que, ao mesmo tempo, se tenha uma visão ampla e específica acerca de um tema.

Os mapas mentais são perfeitos para o planejamento, já que cada ponto no mapa pode aprofundar numa área em particular relacionada com o tema principal. Ele permite explorar o assunto, encontrar conexões entre diferentes áreas, concentrar-se em 
detalhes, sem perder a visão geral. Quando as conexões entre os conceitos se apresentam de forma radial, promove-se uma aproximação reflexiva para a organização dos dados, eliminando, assim, o estímulo inicial de estabelecer um quadro conceitual intrínseco apropriado para o trabalho específico. Por isso, o mapa mental atua como um modelo cognitivo ou uma rede semântica, ainda que sem restrições formais na classe de vinculados utilizados. (BUZAN, 2005; 2009) A figura 1 apresenta a estrutura de um mapa mental, e a figura 2 um exemplo de como criar um mapa mental.

Figura 1 - A estrutura de um mapa mental.

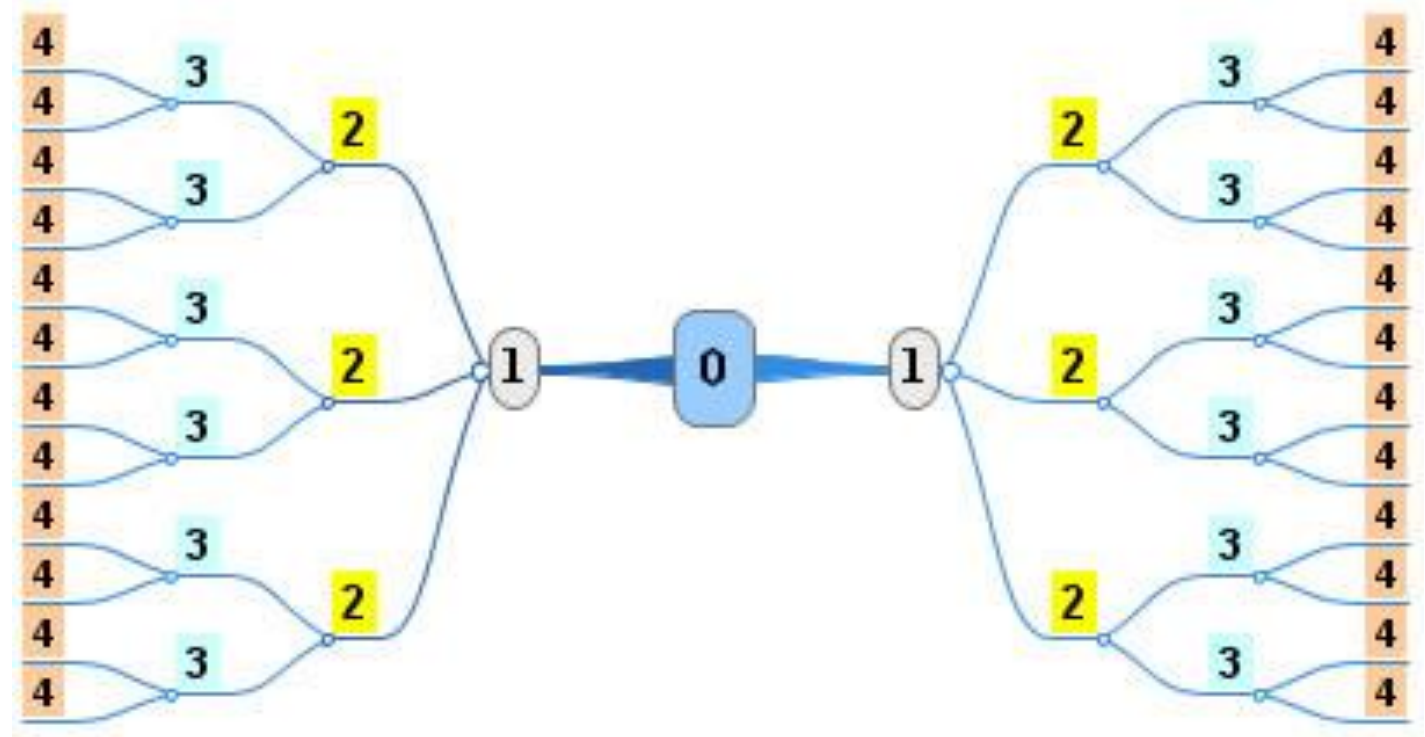

Fonte: www.mapasmentais.com.br

Figura 2 - Exemplo de um mapa mental.

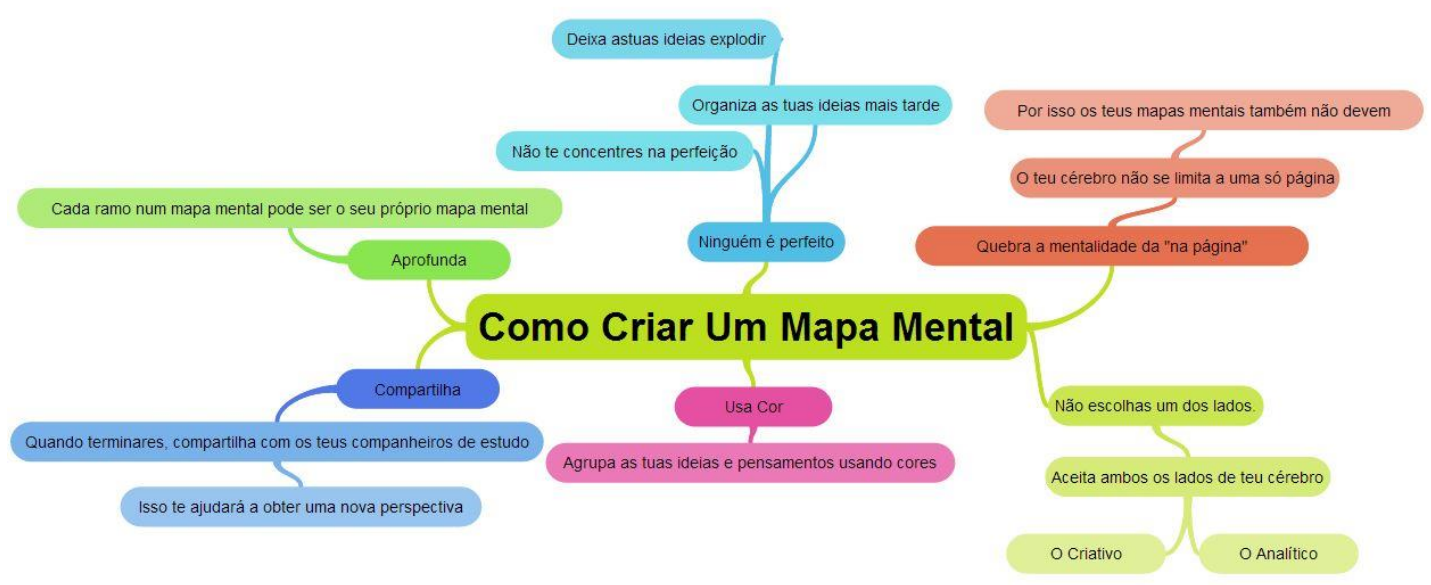

Fonte: http://www.tecnologiapedagogica.com.br/2016/01/examtime.html 
Por meio da figura 2, podemos observar como as informações foram organizadas e hierarquizadas pelo mapa mental, mostrando que ele é uma ferramenta importante na primeira etapa de um projeto de Design. A seguir, será abordada uma revisão bibliográfica sobre a importância do Design na área projetual.

\section{DESIGN: atividade de projeto}

O design é caracterizado como um campo híbrido que atua na conexão entre informação, artefato, usuário e sistema, tendo como natureza a atividade de projeto, capaz de viabilizar soluções sistêmicas e criativas para os desafios que são propostos. (BOMFIM, 1995)

De acordo com Bomfim (1995), a atividade de projeto envolve três aspectos principais: os objetivos que vão determinar "para que" ou "para quem"; o conteúdo que apresenta a explicação do "o que", pela interpretação dos objetivos, do estabelecimento das funções e da estrutura do produto; e "como" a metodologia será desenvolvida no projeto. A figura 3 apresenta essas informações. 
Figura 3 - A atividade de projeto envolve três aspectos principais.

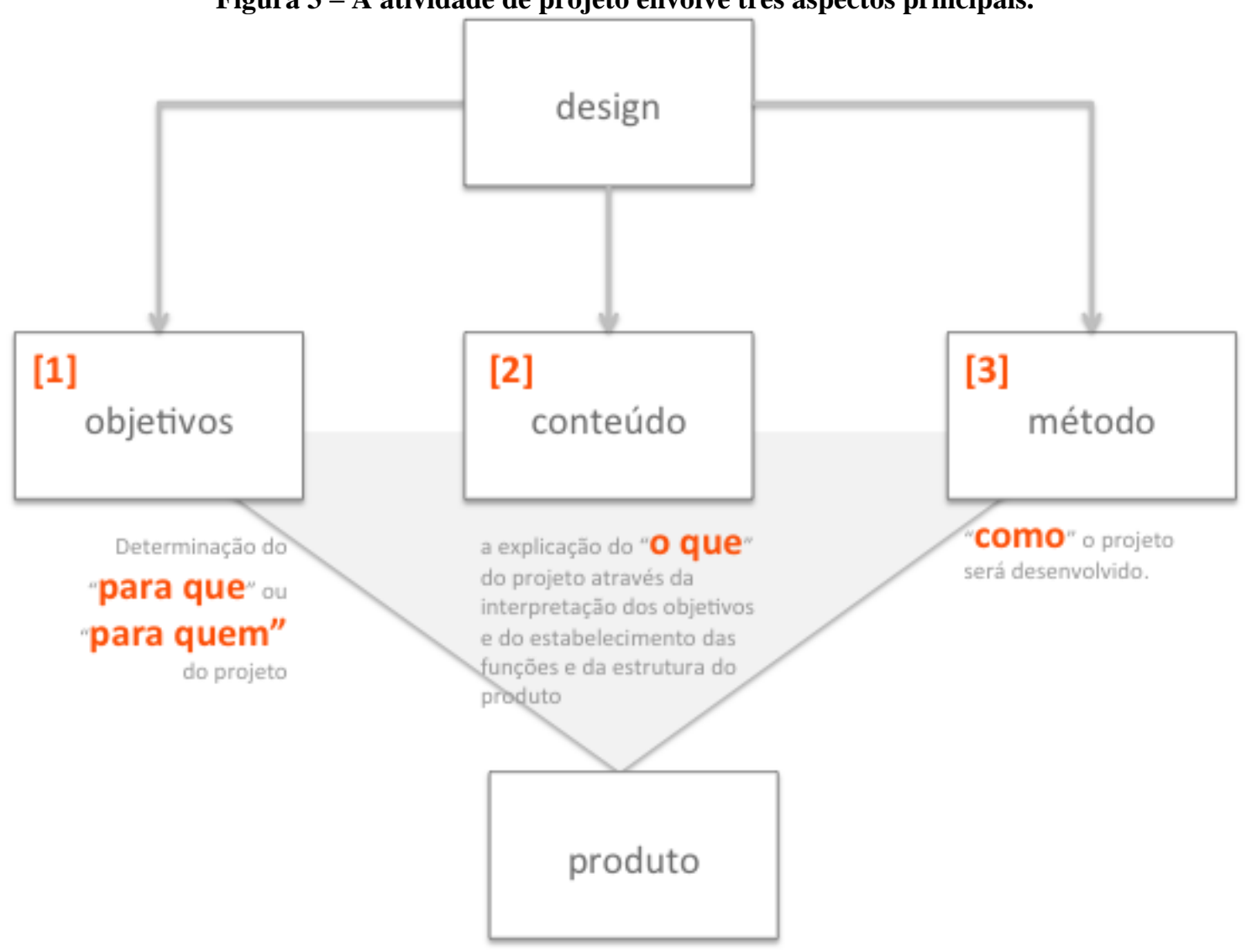

Fonte: Elaborado pelos autores, com base na pesquisa realizada.

A metodologia de projeto enfatiza várias etapas, conforme parte da identificação de um problema, sendo que após vários tipos de análise é que se define o problema e se realiza o anteprojeto, geração de alternativas e chegando ao produto. A figura 4 apresenta uma síntese de vários conceitos do processo de design. 


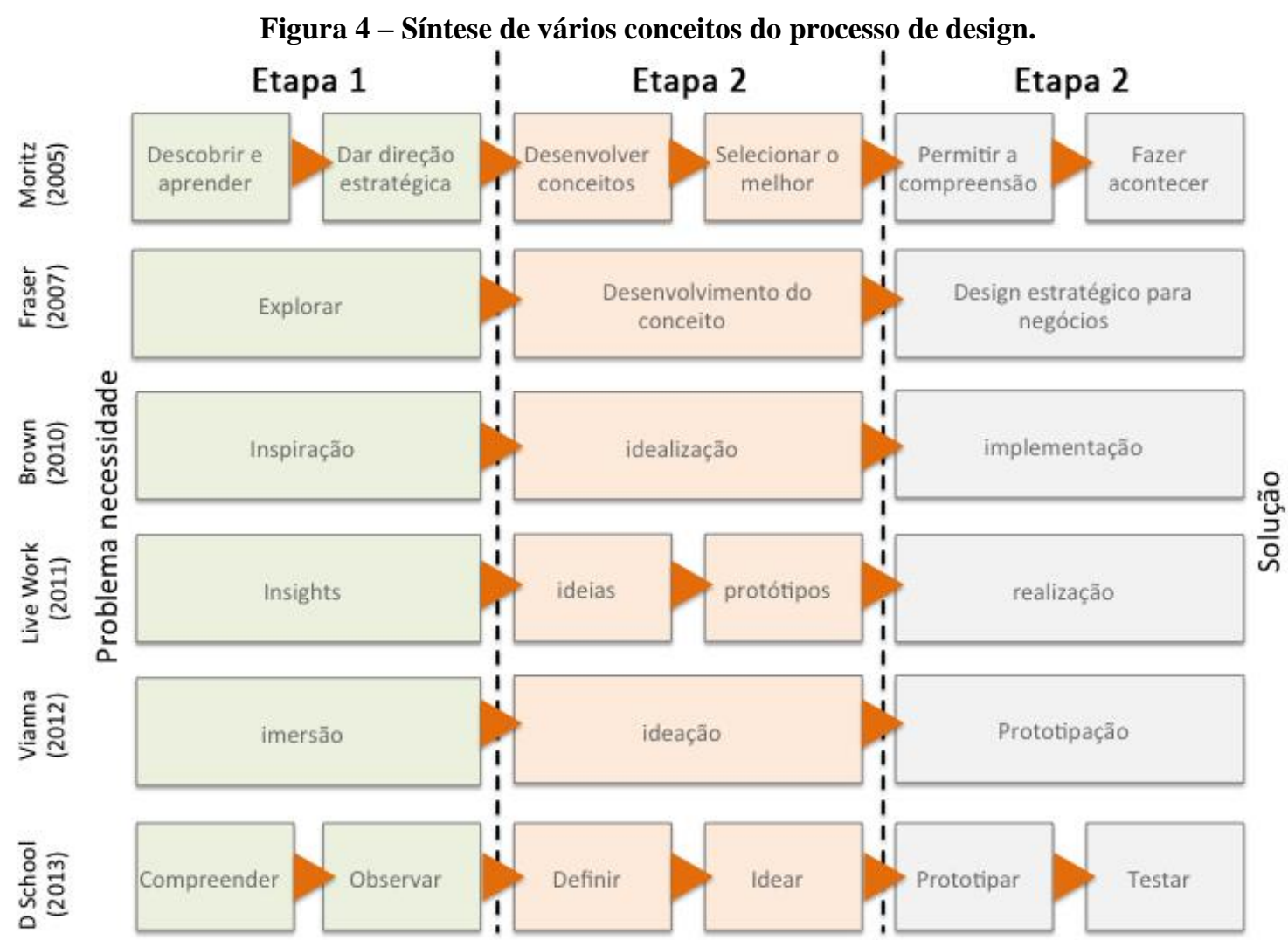

Fonte: Elaborado e adaptado pelos autores, com base na pesquisa realizada.

Os mapas mentais devem ser desenvolvidos na etapa um, no sentido de explorar o tema, observando, descobrindo, aprendendo, compreendendo o assunto. No caso deste trabalho, são as roupas funcionais tendo em vista o conforto e bem-estar das mulheres. E, a partir de então, dar uma direção ou direções estratégicas no desenvolvimento de conceitos e ideias, com propostas de projetos, protótipos, etc.

\section{ROUPAS FUNCIONAIS E O CONFORTO FEMININO}

$\mathrm{O}$ debate a respeito dos aspectos funcionais do vestuário tem alimentado a indústria da moda na disputa conceitual entre forma e função. A forma até agora tinha levado vantagem no que se refere ao design de produtos de moda. Porém, nos dias atuais, estimula-se o reconhecimento do ganho que o usuário pode ter ao vestir uma roupa funcional, evidenciando a importância da função da roupa. (OURIVES et al, 2016)

As roupas funcionais são fabricadas com modelagem e tecidos cientificamente desenvolvidos, trazendo benefícios úteis à saúde e qualidade de vida para as pessoas, indo além das antigas funções estéticas. 
A preocupação com a funcionalidade da roupa feminina pertence a um passado longínquo, aproximadamente 400 a.C., passando por várias fases (vide figura $5)$.

\section{Figura 5 - Fases.}
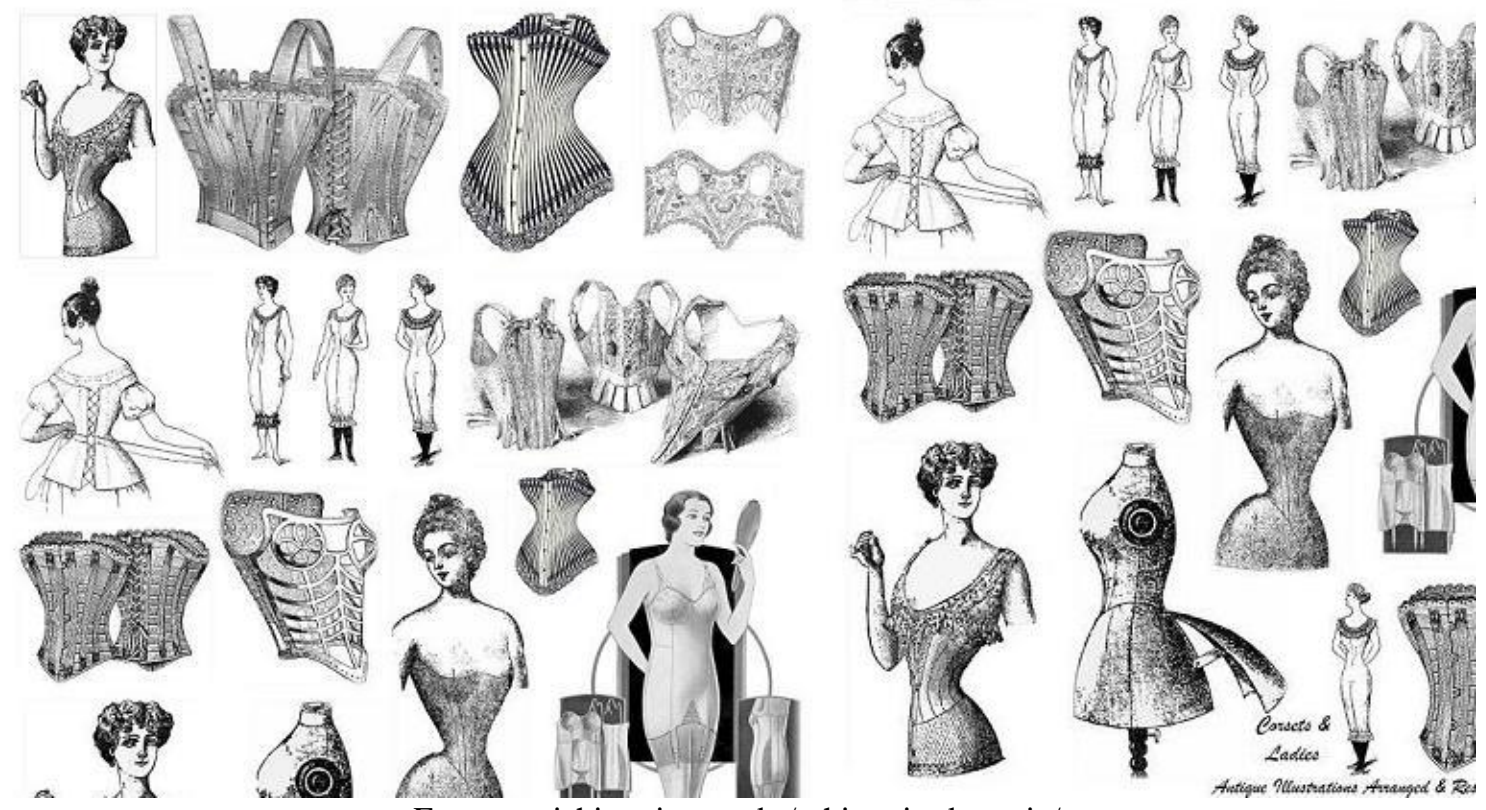

Fonte: maishistoria.com.br/a-historia-do-sutia/

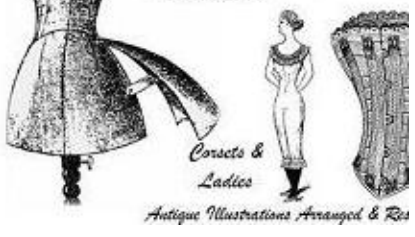

O primeiro registro de roupa específica para as mamas femininas foi uma contribuição dos gregos, por meio de uma faixa de linho que envolvia o busto, chamada de "mastodeton" (vide figura 6), e que tinha a função de cobrir e segurar as mamas. (EWING, 1989) 
Figura 6 - Mosaico de Villa Armena, Sicília, 400 a.C.

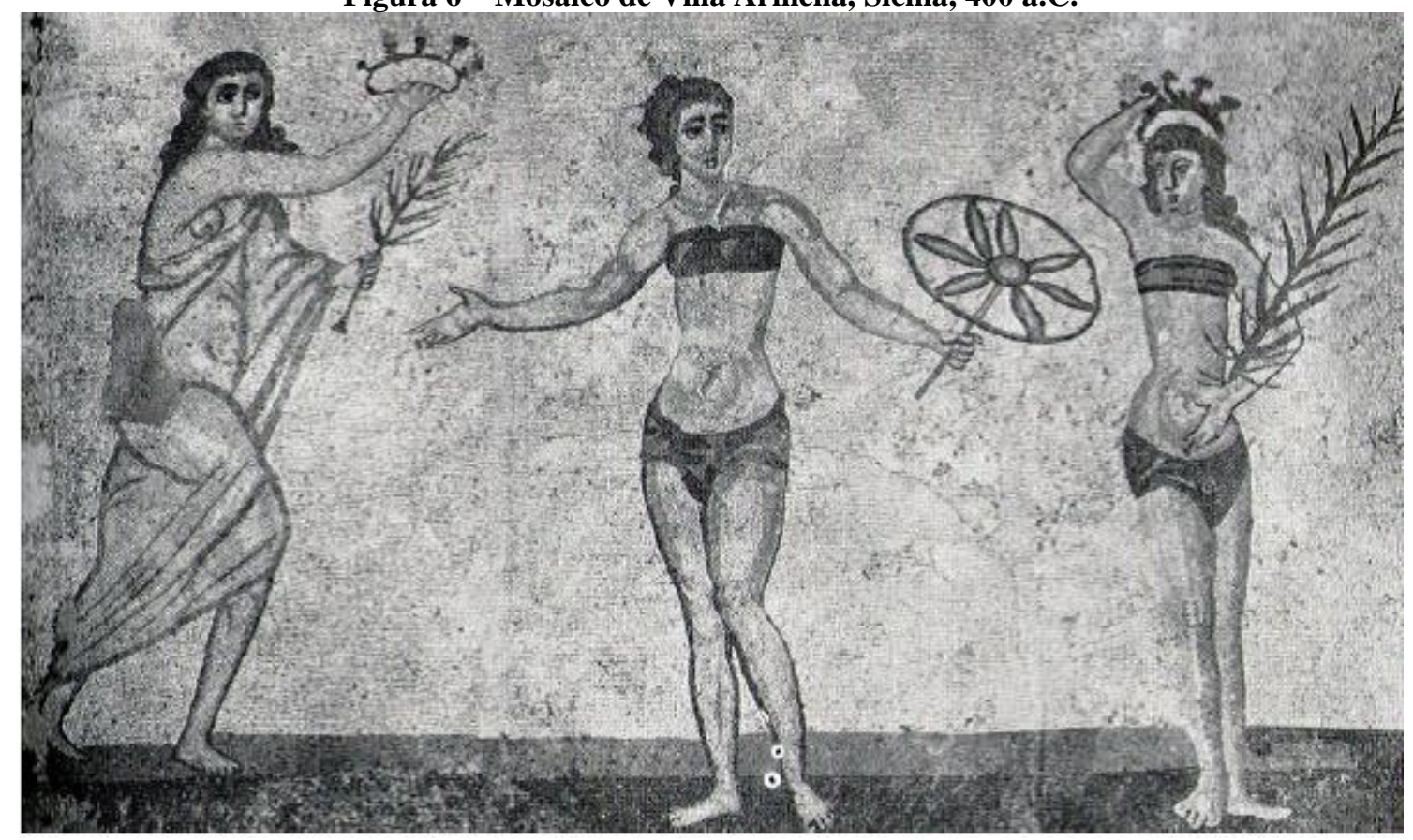

Fonte: Ewing (1989).

Entre 1750 a.C e 1400 a.C., surgiu algo parecido com o espartilho que apertava a região do abdômen indo até a altura das mamas. $\mathrm{O}$ uso desse tipo de roupa íntima variava em modelos (vide figura 7) e foi até o século XX. (EWING, 1989)

Figura 7 - Corset do século XVI.

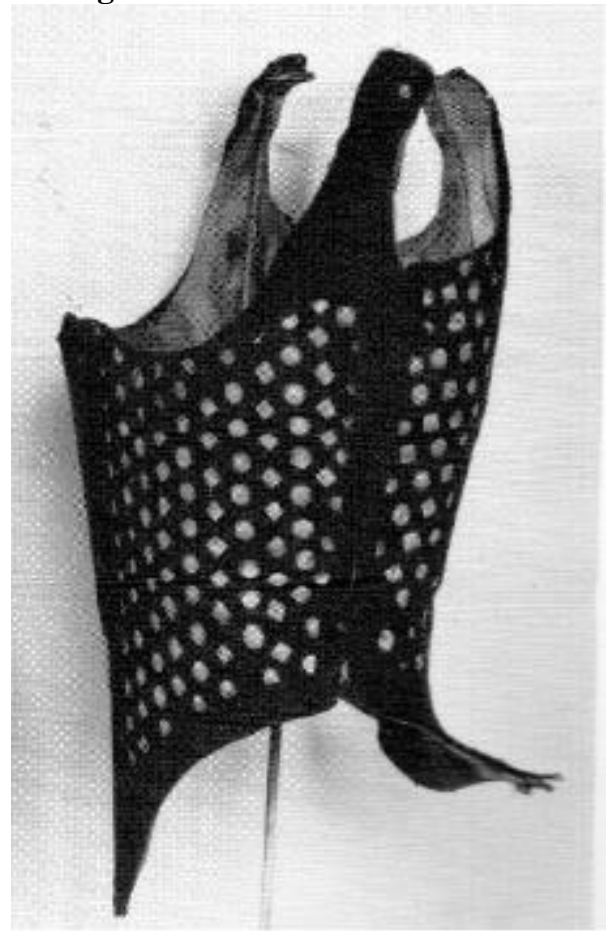

Fonte: Ewing (1989). 
Em 1889, Herminie Cadolle decidiu cortar em duas partes o tradicional espartilho, dando as primeiras configurações do que viria a ser o primeiro sutiã (vide figura 8).

Figura 8 - Primeira configuração e BacklessBra.
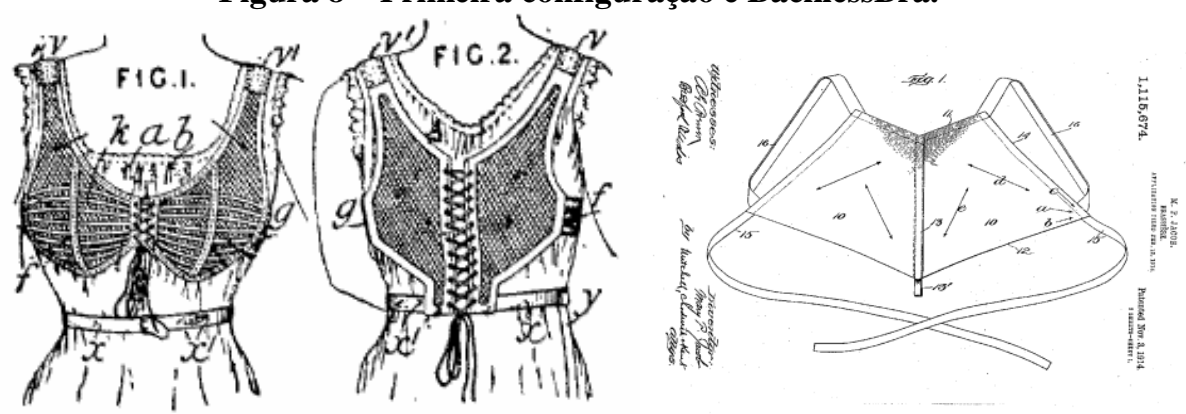

Fonte: http://maishistoria.com.br/a-historia-do-sutia/

No século XX, por volta de 1914, surge a preocupação com o conforto das mamas femininas, pelo protótipo da americana Mary Phelps Jacob, denominado na época de "brassiere". Ela criou, a partir de lenços, um protótipo que era macio, curto e acomodava separadamente as duas mamas, esse modelo era chamado de "BacklessBra", como mostra a figura 8. (EWING, 1989) A forma "brassiere" percorreu décadas e transformações (vide figura 9).

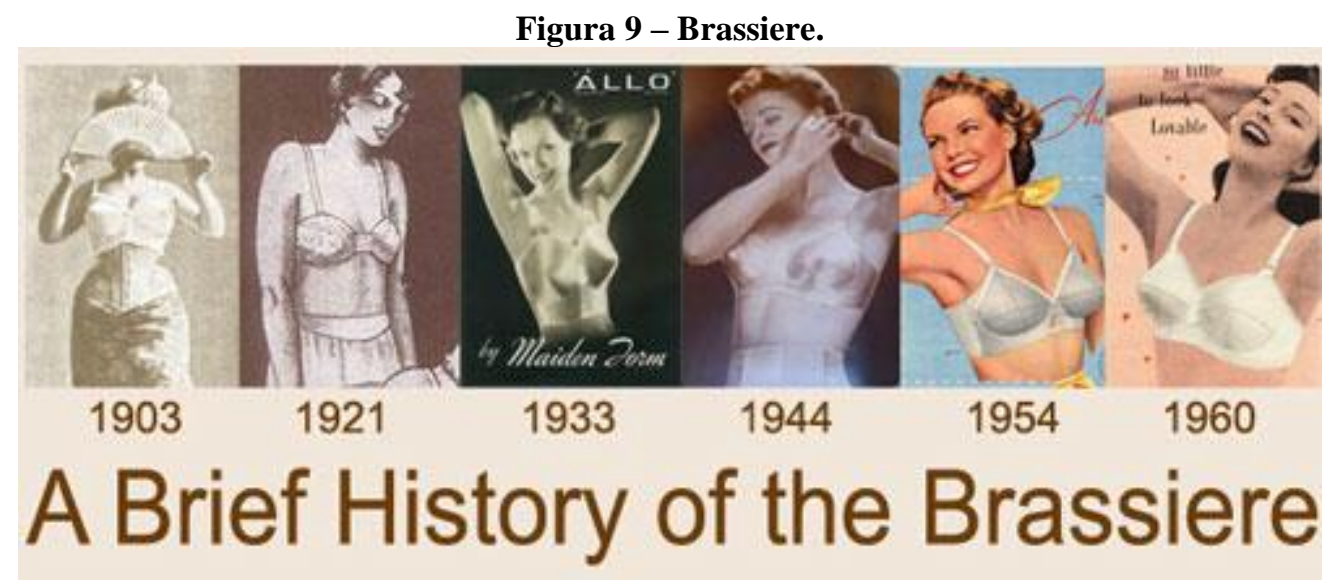

Fonte: http://maishistoria.com.br/a-historia-do-sutia/

Em 1926, surge o modelo criado por Rosalin Klin, constituído por duas copas transpassadas na frente, com caimento e uso de elásticos. Porém, foi o modelo de Kestos o primeiro a modelar as mamas pelas copas (vide figura 10). (EWING, 1989) 


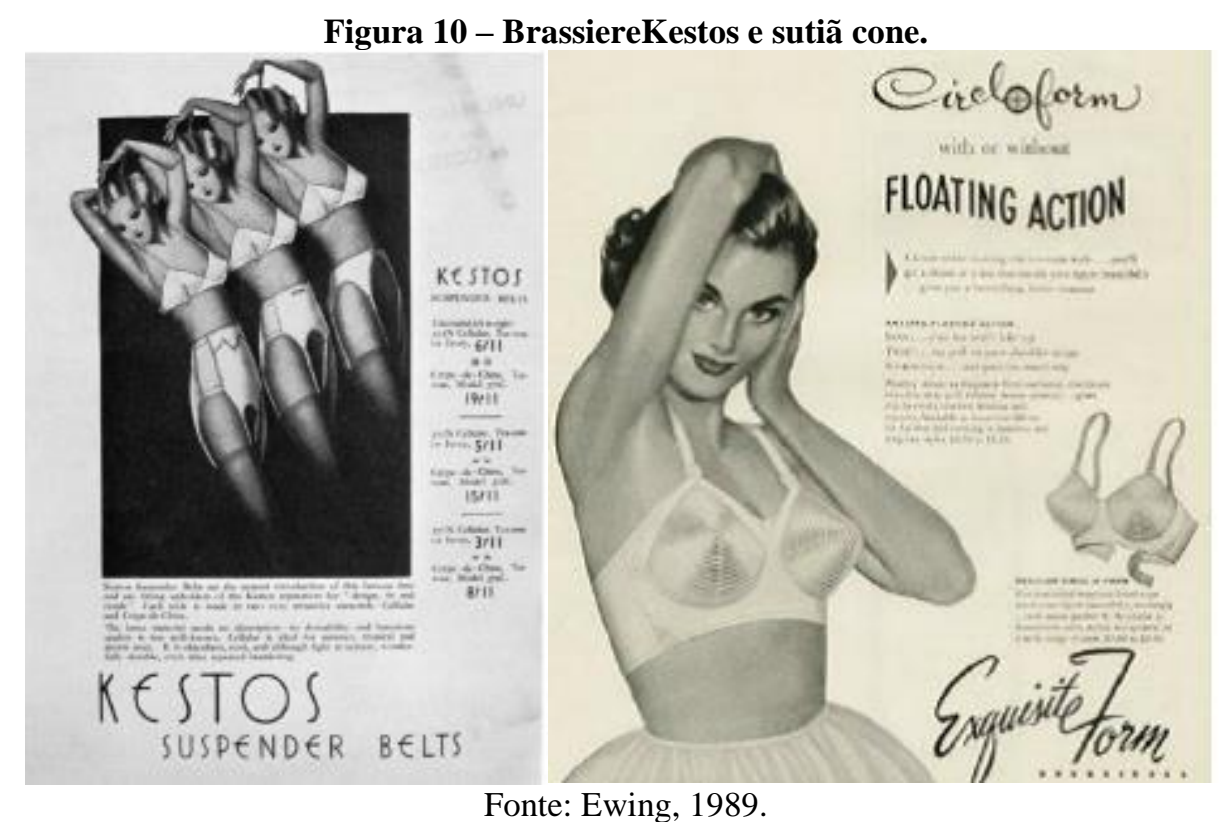

A partir de 1935, utilizado até os dias atuais, a Warner Bross Corset Company introduziu no mercado uma numeração diferenciada para sutiãs, com base nas medidas do tórax e do busto separadamente. As copas tinham quatro tamanhos diferentes $\mathrm{A}, \mathrm{B}, \mathrm{C}$ e $\mathrm{D}$. Na década de 50 , houve a predominância dos sutiãs com formato de cone (vide figura 10). (EWING, 1989)

Já na década de 70 , ocorre o lançamento do primeiro sutiã de bojo conhecido como "wonderbra". E surge em 1977, a famosa marca Victoria's Secret, específica na moda íntima. E, a partir de 1990 até os dias atuais, existem no mercado várias opções para muitas finalidades e funções. (EWING, 1989)

\section{PROCEDIMENTOS METODOLÓGICOS}

De acordo com Gil (2010), quanto à natureza da pesquisa, o presente trabalho utiliza uma metodologia de pesquisa aplicada, pois busca gerar conhecimento para aplicações práticas de soluções a problemas específicos; quanto à abordagem, como pesquisa qualitativa, pois visa a qualificar os dados coletados, conforme afirma Richardson et al (1999). E, quanto aos objetivos, como pesquisa exploratória, pois tem como finalidade desenvolver, esclarecer e modificar conceitos e ideias, proporcionando maior familiaridade com o problema. (GIL, 2010) 
O presente estudo explorou os conceitos usando o mapa mental (vide figura 11), e os seus resultados foram obtidos pela análise desse mapa, elaborando as diretrizes de projeto.

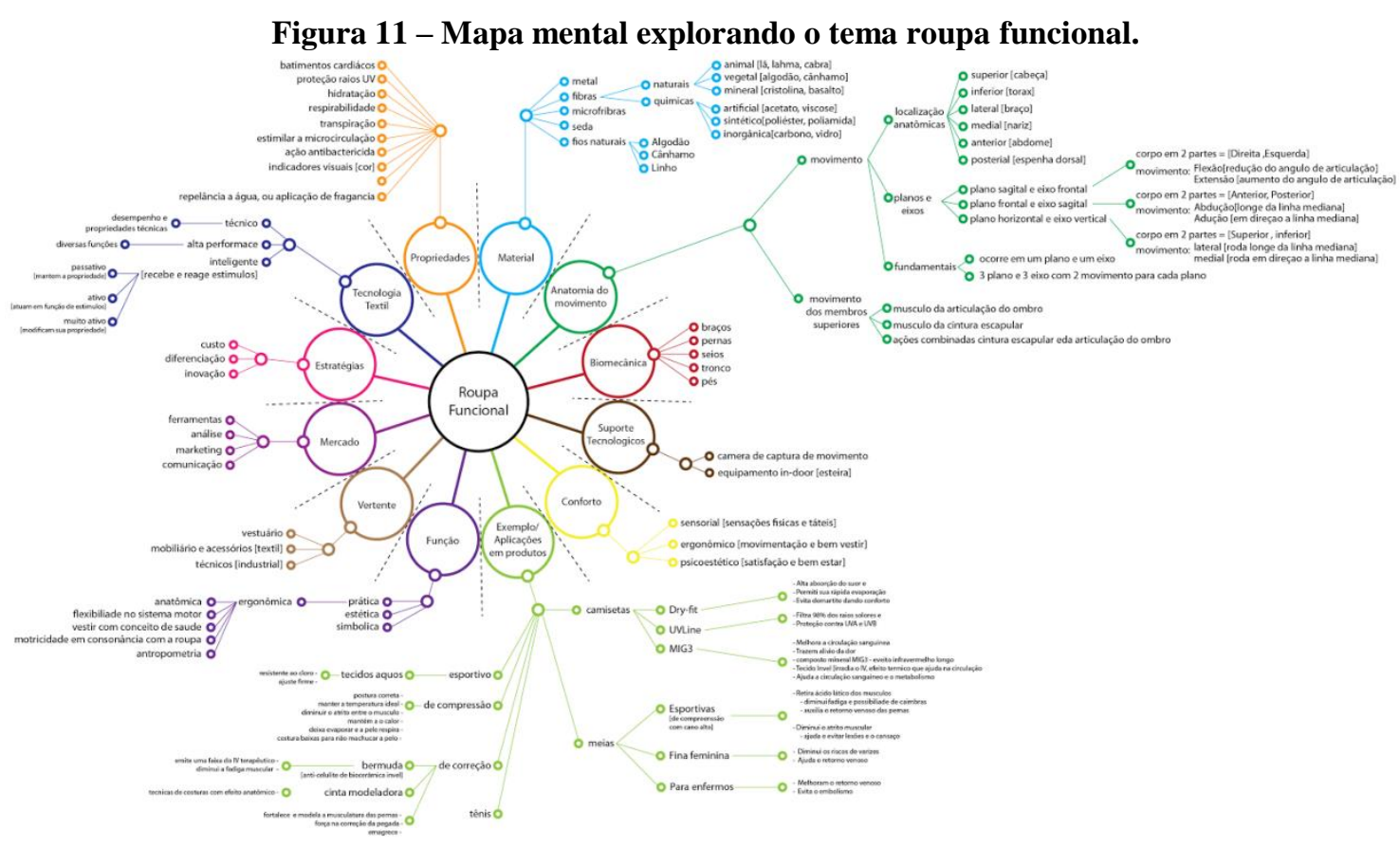

Fonte: Elaborado pelos autores, com base na pesquisa realizada.

O mapa mental foi construído, a partir de pesquisa em revistas, livros, vídeos, etc., realização de entrevistas com as mulheres que praticam esportes, trabalham em fábricas, profissionais da área, entre outros. A finalidade foi explorar o tema roupa funcional, segundo os aspectos: função, propriedades, tecnologias, biomecânica, material, anatomia do movimento, mercado, produtos, conforto e estratégias.

\section{DISCUSSÃO DE RESULTADOS}

A construção do mapa mental forneceu base para a análise da área de informação - do material, anatomia do movimento, função, conforto e aplicação em produtos - a partir do qual foram elaboradas as diretrizes de projeto. Vide quadro 1: 
Quadro 1 - Análise do mapa mental.

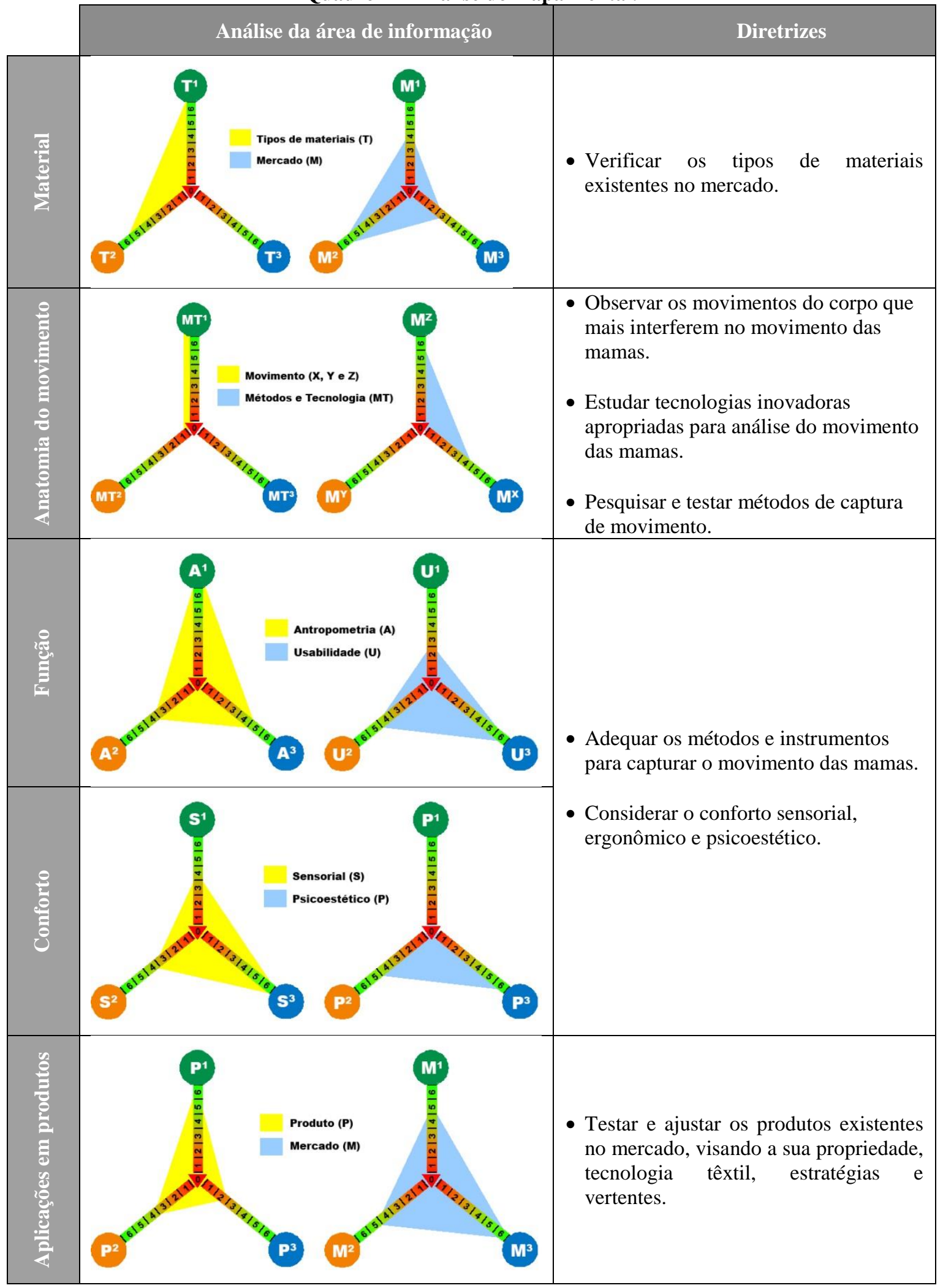

Fonte: Elaborado pelos autores, com base na pesquisa realizada. 
Essas diretrizes serviram como parâmetros para a especificação e elaboração do projeto de roupas funcionais. Por exemplo, ao verificar os tipos de materiais disponíveis no mercado, observou-se que é possível utilizar as fibras, microfibras e as fibras naturais nas roupas. Além disso, esses tipos de materiais podem ajudar e favorecer o conforto durante o movimento em atividade física.

\section{CONCLUSÃO}

A alta tecnologia aplicada ao vestuário está sempre inovando a cada ano, no que se refere às variadas funções para as roupas femininas, como usabilidade em trajes esportivos e íntimos. Os avanços em tecidos inteligentes, modelos diferenciados e alta tecnologia prezam sempre pelo bem-estar do usuário.

A criação de roupas funcionais tem que considerar quatro características fundamentais: a funcionalidade, segurança, bem-estar e conforto das mulheres, tendo em vista as atividades físicas e laborais praticadas por elas. Porém, apesar da grande quantidade de materiais e modelos disponíveis atualmente no mercado, no que diz respeito ao vestuário íntimo e esportivo, ainda existe insatisfação das mulheres em relação a sua funcionalidade e conforto.

Verifica-se que pesquisar e estruturar as informações sobre o tema, visando a requisitos de projeto de roupas funcionais é de grande importância, pois irá adequar os projetos para atividades no trabalho de fábrica, práticas esportivas, etc.

O uso do mapa mental mostrou ser uma ferramenta de grande relevância, no sentido de explorar o tema, observando, descobrindo, aprendendo e compreendendo o assunto. No caso, este trabalho - as roupas funcionais, tendo em vista o conforto e bemestar das mulheres - proporcionou a elaboração de diretrizes para cada área de informação que foi considerada. Essas diretrizes geradas direcionam ao desenvolvimento de conceitos e ideias, com propostas de projetos e protótipos.

Com base no estudo desenvolvido neste trabalho, sugere-se a continuidade pela: realização de pesquisa dos produtos e materiais utilizados para confecção de roupas, que considere o movimento de mamas femininas na realização de práticas laboral e esportiva; utilização de métodos e equipamentos específicos para captura de movimentos de mamas, visando à produção de roupas funcionais; comparação de roupas íntimas e esportivas existentes no mercado em termos de movimento das mamas 
durante as práticas laboral e esportiva; produção de protótipos que inibam o movimento das mamas durante as práticas laboral e esportiva, tendo em vista o conforto e bem-estar das mulheres.

\section{Artigo recebido em Outubro de 2016. Aprovado em Novembro de 2016 DOl:http://dx.doi.org/105965/1982615×10192016070}

\section{REFERÊNCIAS}

AULER, Otavio. A história do sutiã. 2015. Disponível na internet por http em: <www.maishistoria.com.br/a-historia-do-sutia/>. Acesso em: 10 Jun. 2016.

BOMFIM, G. A. Metodologia para Desenvolvimento de Projeto. v. 1. João Pessoa: Universidade federal da Paraíba, 1995.

BUZZAN, Tony. Mapas Mentais e sua elaboração: um sistema definitivo de pensamento que transforma a sua vida. São Paulo: Cultrix, 2005.

BUZZAN, Tony. Mapas Mentais no trabalho: como ser o melhor na profissão e ainda ter tempo para lazer. São Paulo: Cultrix, 2009.

EWING, Elizabeth. Everyday dress: 1650-1900. David \& Charles, 1989.

GIL, Antonio Carlos. Métodos e técnicas de pesquisa social. São Paulo: Atlas, 2010.

INSTITUTO DE DESENVOLVIMENTO DO POTENCIAL HUMANO. Mapas mentais. Disponível na internet por http em: 〈www.mapasmentais.com.br〉. Acesso em: 10 Jun. 2016.

OURIVES, Eliete Auxiliadora Assunção; FIGUEIREDO, Luiz Fernando Gonçalves de; VIEIRA, Milton Luiz Horn; OLIVEIRA, Victor Nassar Palmeira; NISHIDA, Jonathan Ken; FERREIRA, Alais Souza. A captura de movimento como suporte informacional para projeto de roupa funcional feminina. 2016. I Congresso Brasileiro de Pesquisa \& Desenvolvimento em Tecnologia Assistiva.

RICHARDSON, R. J. Pesquisa social: métodos e técnicas. 3. ed. São Paulo: Atlas, 1999. 